\title{
Towards Modeling Sediment Yield and Transport in Tropical Arid \& Semi-Arid Lands (ASAL)
}

\author{
By \\ Sibilike K. MAKHANU* , Shogo MURAKAMI** , Shuichi IKEBUCHI ${ }^{* * *}$ and Hiroji NAKAGAWA****
}

\begin{abstract}
Scarcity of data in sediment budget for arid and semi-arid lands (ASAL) is a recognized fact despite their environmental fragility. There is therefore urgent need for exchange of current knowledge in this field for effective conservation. We present a comparison among published and proposed models for computation of sediment yield and transport due to rainfall runoff for a single storm by using data from 8 storm events of 1986 in Katiorin experimental basin which is located in a semi-arid area of Kenya. We categorize the models into black, grey and white box on the basis of their consideration for physical principles.
\end{abstract}

Keywords: sediment yicld, pick-up rate by rainfall-runoff, stream power.

\section{INTRODUCTION}

Sediment yield by rainfall runoff is caused by rainfall as the primary and the resulting overland flow as the secondary erosive agent. The simple cause-effect phenomenon would therefore give a black box model whose input is rainfall or flow and sediment transport as the output. We classify such like models, in Fig. 1, as black box: RBB and FBB which signify rainfall and flow as the representative parameter respectively. We next classify models which partially explain the erosion phenomenon by grouping two or more parameters of rainfall, slope, slope length and bed material characteristics developed from statistical considerations with or without consideration of dimensional homogeneity as grey models: RGB and FGB. When homogeneity is considered in the empirical developments, the models lie on the borderline between grey and white box models. Finally we consider models derived from physical principles by mathematical analysis of the raindrop impact and flow dynamics as white box models: RWB and FWB.

* Member, MSc., Ph. D, Lecturer, Dept. of Civil Eng., Jomo Kenyatta Univ. of Agri. \& Technology, P.O. Box 62000, Nairobi, Kenya (formerly, Graduate Student, Division of Global Env. Eng., Kyoto Univ., Sakyo-ku, Kyoto 606-01) ** Member, M. Eng., Ph. D, Research Associate, Division of Global Env. Eng., Kyoto Univ., Sakyo-ku, Kyoto 606-01, Japan *** Member, M. Eng., Ph. D, Professor, Water Resour. Res. Center, Disaster. Prev. Res. Inst. , Kyoto Univ., Gokasho, Uji 611 **** Member, M. Eng., Ph. D, Professor, Dept. of Civil Engineering, Ritsumeikan University, Kusatsu 525. 


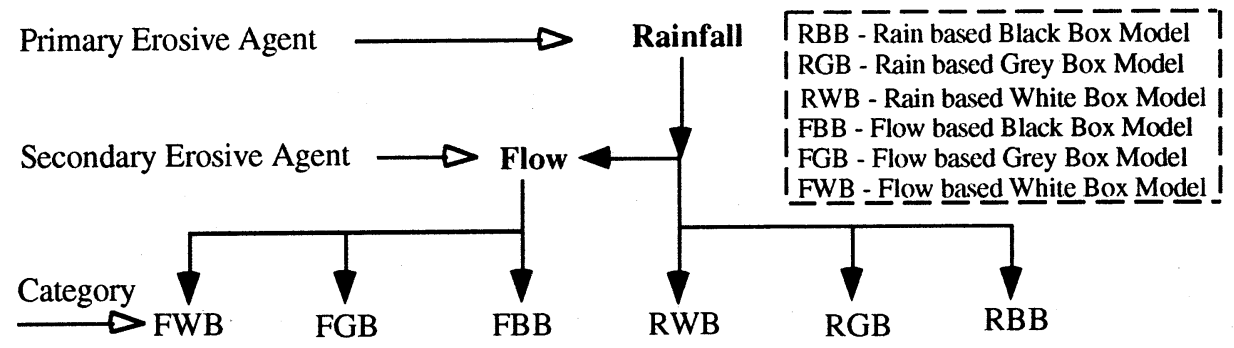

Fig. 1 Classification of Sediment Yield and Transport Models

\section{BRIEF DESCRIPTION OF REPRESENTATIVE MODELS}

\subsection{Black Box Models for Katiorin Experimental Basin}

Bryan et al. (1988) developed two empirical models one based on rainfall volume ( which we code RBB) and the other in the form of a rating curve at the outlet of Katiorin basin (FBB) expressed respectively as follows; $S_{t}=0.049 V_{p}-157 ; C_{s}=42.7 Q^{0.281}$

in which $S_{t}=$ suspended sediment load in tons per storm, $V_{p}=$ rainfall volume in $\mathrm{m}^{3}, C_{s}=$ suspended sediment concentration in $\mathrm{g} / \mathrm{l}$ and $\mathrm{Q}=$ water discharge in $\mathrm{m}^{3} / \mathrm{s}$.

\subsection{Rain Based Grey Box Models}

Ellison (1947) pioneered the development of an empirical model (RGB1) which related rainfall parameters to total sediment yield as follows without consideration of dimensional homogeneity;

$E_{e}=K_{e} V_{e}^{4.33} D^{1.07} I^{0.65}$

in which $E_{e}=$ the amount of soil in tons splashed during a 30-minute period, $K_{e}\left(=3.8 \times 10^{-5}\right)$ is constant of the soil, $\mathrm{V}_{\mathrm{e}}=$ drop velocity in $\mathrm{ft} / \mathrm{s}, \mathrm{D}=$ drop diameter in $\mathrm{mm}$ and $\mathrm{I}=$ rainfall intensity in in $/ \mathrm{hr}$.

Based on dimensional analysis of a raindrop impact on the water surface, Makhanu et al. (1995) proposed the following model (RGB2) for computation of bed load transport and expressed in non-dimensional form as;

$$
q_{B} \prime\left[\sqrt{(\sigma / \rho-1) g d^{3}}\right]=f_{L} \cdot D_{r}^{\mathrm{S}} \cdot\left[1-\left(D_{r c} / D_{r}\right)\right]^{n} ; D_{r}=\frac{w_{f}^{2}}{(\sigma / \rho-1) g d} \cdot \frac{r \sin \theta}{\sqrt{g d}} ; f_{L}=K\left[\left(\frac{L}{d}\right)^{c} \cdot \tan \theta\right]^{e}
$$

in which $\mathrm{s}(=1.75), \mathrm{c}(=2.0), \mathrm{e}(=1.3)$ and $\mathrm{n}(=0.6)$ are experimental constants and terminal raindrop velocity in $\mathrm{m} / \mathrm{s}$ is given by $\operatorname{Best}(1950)$ as: $w_{f}=9.32\left\{1-\exp \left[-(D / 0.177)^{1.147}\right]\right\}$ for $\mathrm{D}$ in $\mathrm{cm}$. The critical rainfall impact parameter $D_{\mathrm{rc}}$ is computed by Eq. (3b) for $r \equiv r_{c}$ from Eq. (4b), $w_{f c}=$ the raindrop final impact velocity for $r_{c}$ and $\mathrm{K}\left(=2.2 \times 10^{-13}\right)$ is a scale parameter to be determined for the particular basin. The rainfall intensity at critical conditions $r_{c}$ is determined from the value of bed shear stress $\tau_{*_{s}}$ necessary to sustain a detached particle in motion. By considering the forces on the particle at stopping instant the value of $\tau_{*_{s}}(=$ $0.013)$ is determined. Other parameters are expressed as follows;

$$
\tau_{*_{s}}=\frac{\sin \theta}{\sigma / \rho-1} \cdot \frac{h(L)}{d} ; r_{c e}=r_{c}-r_{i}=\alpha \cdot \frac{h(L)^{m}}{L} ; \alpha=\sqrt{\frac{8}{\mathrm{f}} g \sin \theta} ; \sqrt{\frac{8}{f}}=B_{r}+\frac{1}{\kappa} \ln \frac{h(L)}{d}-\frac{1}{\kappa}
$$

For a given value of bed material d and slope gradient, the water depth at the end of the slope length $h(L)$ is obtained from Eq. (4a) and hence the net rainfall intensity corresponding to this condition $\mathrm{r}_{\mathrm{c}}$ is evaluated by Eq. (4b) in which $r_{i}=$ infiltration rate, $r_{c e}=$ effective rainfall at critical conditions, $m=3 / 2, B_{r}(\equiv 8.5)$ is constant of integration in the log-law velocity profile, $\mathrm{f}=$ friction factor and $\kappa(\equiv 0.41)$ is the von Karman constant. 


\subsection{Flow Based Grey Box Models}

We propose a bed load model based on stream power which is expressed as follows (FGB);

$$
\begin{aligned}
& q_{*} I_{*}=\frac{r L}{\sqrt{(\sigma / \rho-1) g d^{3}}} \cdot \frac{i_{b}}{\sigma / \rho-1} \\
& q_{B e^{*}} \equiv \frac{q_{B e}}{\sqrt{(\sigma / \rho-1) g d^{3}}}=A \cdot\left[q_{*} I_{*}-\left(q_{*} I_{*}\right)_{c}\right]^{\gamma}
\end{aligned}
$$

in which $\mathrm{q}(\equiv \mathrm{r} . \mathrm{L})$ is unit discharge, $\mathrm{A}(=0.0014)$, $\mathrm{i}_{\mathrm{b}}=$ bed slope, $\gamma(=5 / 3)$ and $\left(q_{*} I_{*}\right)_{c}(=0.981)$ are calibration constants (Fig. 2). Though $\gamma(=5 / 3)$ is the same case of the fluvial channel, A and $\left(q_{*} I_{*}\right)_{c}$ are different from the values for fluvial channel because of the rainfall impact.

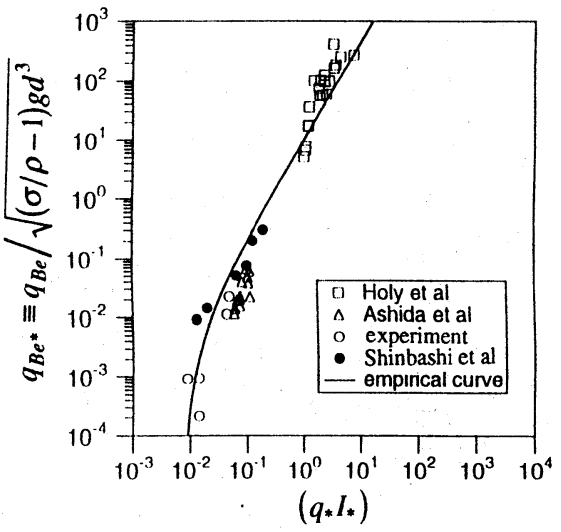

Fig. 2 Emphirical Curve for Sediment Transport Rate Based on Stream Power

\subsection{White Box Models Based on Rainfall and Flow}

In order to model overland flow on a plane, we define the typical slope length $\mathrm{L}$ in white box models based on a kinematic cascade. Thus, the basin is sub-divided into an appropriate number of elements each with an approximate length L. For Katiorin basin, Bryan (1988) subdivided the basin into 18 elements each with a third order stream being the main channel. The typical length of slope was 50 to $80 \mathrm{~m}$. We thus adopt $L=50 \mathrm{~m}$ for the 18 elements in this investigation on white box models. We replace the water depth by the mean overland flow depth in bed load transport models such as that of Ashida et al. (1978) (FWB1) as follows;

$$
q_{B e^{*}}=\frac{12-24 \sqrt{i_{b}}}{\cos \theta} \cdot \tau_{*}^{\left(1.5-\sqrt{i_{o}}\right)} \cdot\left(1-\alpha_{o}^{2} \cdot \frac{\tau_{*_{c}}}{\tau_{*}}\right) \cdot\left(1-\alpha_{o} \cdot \sqrt{\frac{\tau_{*_{c}}}{\tau_{*}}}\right) ; \tau_{*}=\frac{\sin \theta}{\sigma / \rho-1} \frac{h_{m}}{d} ; \tau_{*_{c}}=0.04 \times 10^{1.72 \tan \theta}
$$

in which $\tau_{*}=$ non-dimensional bed shear stress, $\tau_{*_{c}}=$ critical non-dimensional bed shear stress and $\alpha_{o}(=$ $0.92)$ is an empirical constant. The depth at the end of the slope $h(L)$ and the mean flow depth are approximated from the kinematic flow hydrograph as follows for $\mathrm{m}=3 / 2$;

$h(L)=\left(r_{e} . L / \alpha\right)^{1 / \mathrm{m}} ; \mathrm{h}_{\mathrm{m}}=0.6 h(L)$

Based on the hydraulics of overland flow, Komura (1976) proposed the following model (FWB2);

$$
E_{v}=\left(K_{k} C_{A} C_{E} / d_{m}\right) \cdot\left(f^{\prime} r\right)^{15 / 8} L^{3 / 8} S_{o}^{3 / 2}
$$

in which $E_{\mathrm{v}}=$ slope erosion rate in $\mathrm{m}^{3} / \mathrm{hr} / \mathrm{m}^{2}, \mathrm{~K}_{\mathrm{k}}\left(=1.8 \times 10^{-11}\right)$ is a calibration constant, $\mathrm{d}_{\mathrm{m}}=$ mean sediment size of the slope material in $\mathrm{mm}, \mathrm{C}_{\mathrm{A}}(=0.3)$ is the bare soil area ratio, $\mathrm{C}_{\mathrm{E}}(=10)$ is the erodibility coefficient, $\mathrm{f}^{\prime}=$ the runoff coefficient, $\mathrm{L}=$ slope length in $\mathrm{m}, \mathrm{S}_{\mathrm{O}}=$ bed gradient and $\mathrm{r}=$ gross rainfall intensity in $\mathrm{mm} / \mathrm{hr}$.

We propose the following mathematical model based on detachment rate by rainfall and by flow as separate sub-systems with a common deposition process through the same step length $\Lambda(\cong 50 \sim 100 d)$, (FWB3);

$$
q_{B}(x)=q_{B r}(x)+q_{B f}(x) ; \frac{d q_{B r}(x)}{d x}=\frac{q_{B r e}(x)-q_{B r}(x)}{\Lambda} ; \frac{d q_{B f}(x)}{d x}=\frac{q_{B f e}(x)-q_{B f}(x)}{\Lambda}
$$

in which the equilibrium sediment transport rates are uniquely related to the bed shear stress as follows ;

$$
q_{B f e}(x)=\frac{A_{3}}{A_{2}} p_{s f}(x) \Lambda d ; q_{B r e}(x)=\frac{A_{3}}{A_{2}} p_{s r}(x) \Lambda d
$$

The pick-up rate due to flow depth (sub-script f) of Nakagawa and Tsujimoto (1980) is as follows ;

$$
p_{s f^{*}}(x)=p_{s f}(x) \sqrt{d /[(\sigma / \rho-1) g]}=F_{o} \tau_{*}(x) \cdot\left\{1-\frac{k_{2} \tau_{* c}}{\tau_{*}(x)}\right\}^{m^{\prime}} ; \tau_{*}(x) \equiv \frac{\sin \theta}{\sigma / \rho-1} \cdot \frac{h(x)}{d} ; \mathrm{h}(\mathrm{x}) \equiv\left(r_{e} \cdot x / \alpha\right)^{1 / m}
$$




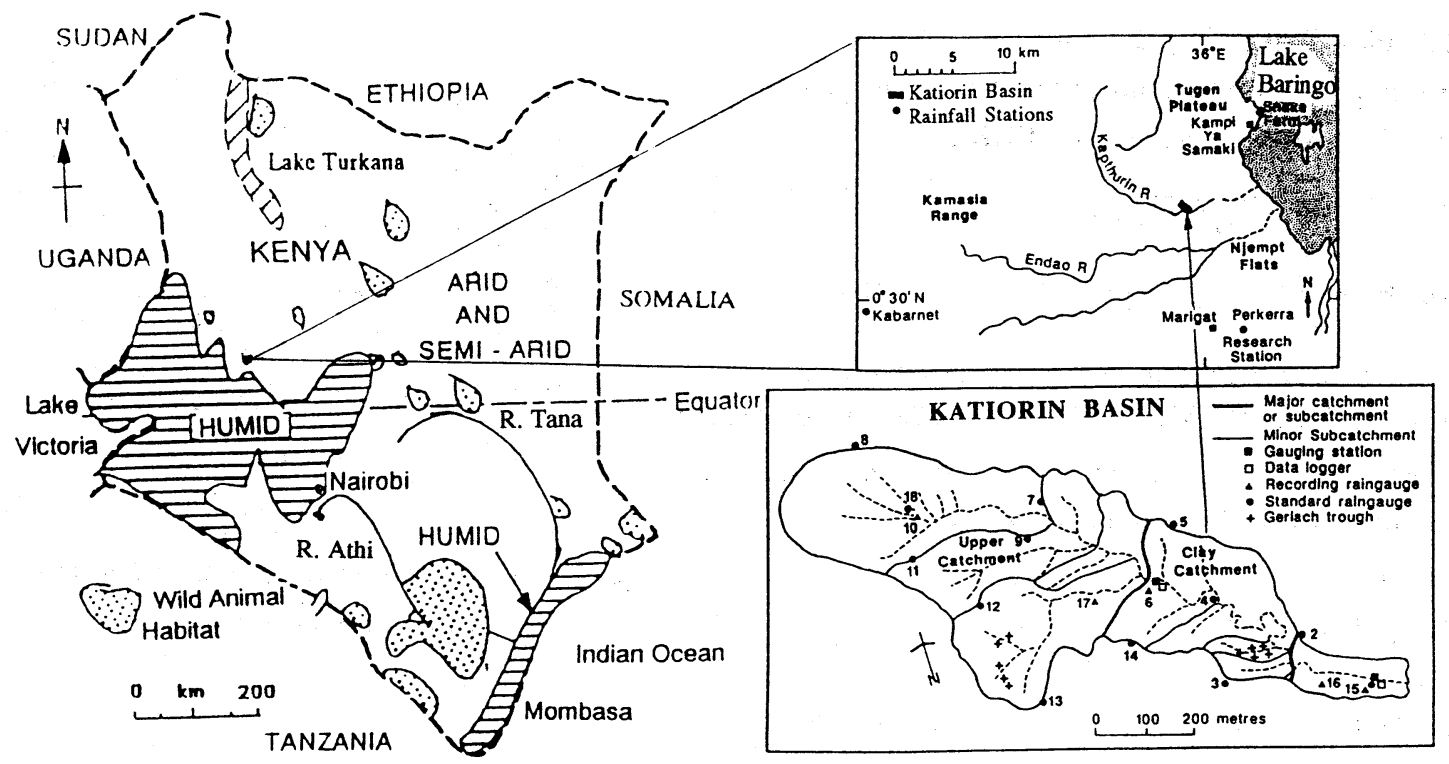

Fig. 3 Location of Katiorin Experimental Basin

in which $\mathrm{F}_{\mathrm{o}}=0.03, \mathrm{k}_{2}=0.7$ and $\mathrm{m}^{\prime}=3.0$. The pick-up rate due to rainfall impact (sub-script $\mathrm{r}$ ) is given as follows based on the probability of a sand particle being detached within the area of raindrop impact;

$$
p_{s r *}(x)=p_{s r}(x) \sqrt{d /[(\sigma / \rho-1)] g}=\frac{A_{2}}{A_{3}} \cdot \frac{r}{\sqrt{(\sigma / \rho-1) g d}}\left(\frac{d}{D}\right)^{3} \cdot N_{o}(x)
$$

in which $\mathrm{A}_{2}, \mathrm{~A}_{3}(=\pi / 4$ and $\pi / 6$ for a sphere respectively) are two and three-dimensional geometric coefficients respectively and $N_{0}(x)=$ the number of detached particles at distance $x$ in the direction of flow which is expressed as follows based on mechanics of flow by Fukada et al. (1992);

$$
N_{o}(x)=\left(\frac{D}{d}\right)^{3} \frac{A_{k}}{(\sigma / \rho-1)} \frac{w_{f}^{2}}{g H_{\max }}\left\{0.38-0.79 A_{I}^{1 / 3}\left(\frac{h(x)}{H_{\max }}\right)^{2 / 3}+0.33 A_{I}\left(\frac{h(x)}{H_{\max }}\right)^{2}\right\} ; H_{\max }=\left(2 E_{o} / \rho g \pi\right)^{1 / 4}
$$

in which $E_{o} \equiv 1 / 2 \rho A_{3} D^{3} w_{f}^{2}$ in $\mathrm{J}$ is the kinetic energy of rainfall, $A_{l} \equiv I_{o} / \sqrt{g H_{\max }^{3}}, A_{\mathrm{k}}=0.028$ and $\mathrm{I}_{0}=0.72$.

\section{KATIORIN EXPERIMENTAL BASIN}

Katiorin experimental basin at an altitude of $947 \mathrm{~m}$ above sea level is located on the west of Lake Baringo in Kenya at latitude $0^{\circ} 33^{\prime} \mathrm{N}$ and longitude $36^{\circ} \mathrm{E}$ (Fig. 3). It has an area of $0.33 \mathrm{~km}^{2}$ and oblong with a shape factor of about 0.65 . The length of the basin is about $1300 \mathrm{~m}$, with a perimeter of $3000 \mathrm{~m}$ and average width of $200 \mathrm{~m}$. Two river gauging stations are located for the upper sub-basin with an area of $0.21 \mathrm{~km}^{2}$ and the lower sub-basin which is $0.09 \mathrm{~km}^{2}$. The upper sub-basin has a general slope of $10^{\circ} \sim 26^{\circ}$ with slope lengths of less than $50 \mathrm{~m}$. The soils are mainly silty clay with minor sands which generate much runoff when too dry due to surface sealing or when wet. The soils in the lower sub-basin constitute a thin alluvial layer with sodic smectile and rich in mudstone. The main river channel in the lower sub-basin has a slope of $2{ }^{\circ} \sim 3^{\circ}$ with general slope lengths of less than $80 \mathrm{~m}$. The basin relief is 0.063 with a median grain diameter of about $\mathrm{d}_{50}=1.4 \mathrm{~mm}$ with a mass density $\sigma=1500 \mathrm{~kg} / \mathrm{m}^{3}$. The basin had a vegetation cover of about $20 \%$ in 1986 being composed mainly of annual grasses and shrubs. The Manning's resistance coefficient was about $0.018 \sim 0.04$. 
Table 1 Details of Rainfall Runoff and Sediment Transport Rates (adapted from Bryan, 1988)

\begin{tabular}{|c|c|c|c|c|c|c|c|c|c|c|c|}
\hline \multicolumn{2}{|c|}{ Storm (1986) } & \multirow{2}{*}{$\begin{array}{c}\mathrm{r} \\
(\mathrm{mm} / \mathrm{hr})\end{array}$} & \multirow{2}{*}{$\begin{array}{c}\mathrm{t}_{\mathrm{R}} \\
\text { (min.) }\end{array}$} & \multirow[t]{2}{*}{$\mathrm{f}^{\prime}$} & \multirow{2}{*}{$\begin{array}{c}Q_{\max } \\
\left(\mathrm{m}^{3} / \mathrm{s}\right)\end{array}$} & \multicolumn{3}{|c|}{ ** } & \multicolumn{3}{|c|}{$* * *$} \\
\hline No. & Date & & & & & $q_{s}^{\prime}$ & $q_{B}^{\prime}$ & $q_{T}^{\prime}$ & $q_{s^{*}}$ & $q_{B^{*}}$ & $q_{T^{*}}$ \\
\hline 1 & 11 April & 66 & $\overline{18.2}$ & 0.56 & 2.80 & 553 & $\frac{15}{47}$ & 600 & 3.783 & 0.322 & 4.104 \\
\hline 2 & 28 April & 42 & 38.6 & 0.49 & 1.40 & 430 & 37 & 467 & 1.387 & 0.119 & 1.506 \\
\hline 3 & 15 May & 42 & 40.0 & 0.48 & 0.89 & 218 & 31 & 249 & 0.678 & 0.096 & 0.775 \\
\hline 4 & 28 July & 36 & 33.3 & 0.35 & 2.20 & 490 & 22 & 512 & 1.832 & 0.082 & 1.914 \\
\hline 5 & 11 Aug. & 48 & 25.0 & 0.38 & 1.80 & 332 & 24 & 356 & 1.653 & 0.120 & 1.773 \\
\hline 6 & 12 Aug. & 12 & 32.0 & 0.66 & 1.50 & 340 & 28 & 368 & 1.323 & 0.109 & 1.432 \\
\hline 7 & 13 Aug. & 60 & 28.0 & 0.66 & 2.10 & 810 & 40 & 850 & 3.602 & 0.178 & 3.780 \\
\hline 8 & 14 Aug. & 30 & 26.0 & 0.29 & 0.30 & 48 & 12 & 60 & 0.230 & 0.058 & 0.287 \\
\hline
\end{tabular}

$*^{* *}=$ measured sediment discharge in $\mathrm{t} / \mathrm{km}^{2} ; * * *=$ non-dimensional sediment discharge.

The annual rainfall regime in Katiorin basin is bi-modal with peaks in April/May and July/August during which 27 and $28 \%$ of the mean annual rainfall of $650 \mathrm{~mm}$ is received respectively. The annual potential evapotranspiration is $1900 \mathrm{~mm}$. Thus based on the $\mathrm{U}_{\mathrm{ai}}$, UNESCO aridity index which classifies arid climates on the basis of rainfall to evapotranspiration ratio of less than 0.5 , it is a semi-arid climate with $U_{a i}=0.34$.

\section{DETAILS OF MEASURED RAINFALL, DISCHARGE AND SEDIMENT YIELD}

The last three columns in Table 1 for non-dimensional sediment discharge per unit width were computed based on total length of basin $L^{\prime}=1300 \mathrm{~m}, \mathrm{~d}_{50}=1.4 \mathrm{~mm}$ and $\sigma=1500 \mathrm{~kg} / \mathrm{m}^{3}$ ). The maximum 10 minute rainfall intensity is used as the representative rainfall intensity since the time of concentration $t_{c}$ for the basin is $10 \sim 15$ minutes. However, $t_{c}$ is also dependent on storm dynamics (Makhanu, 1991). The effective rainfall duration $t_{R}$ was computed to keep the total amount of rainfall constant as those used by Bryan (1988) in Eq. (1a).

$q_{B^{*}}=q_{B}^{\prime} \cdot F_{a} ; \quad q_{s^{*}}=q_{s}^{\prime} \cdot F_{a} ; \quad q_{T^{*}}=q_{T}^{\prime} . F_{a} ; \quad F_{a} \equiv L^{\prime} / 1000 \sigma\left(60 t_{R}\right) \sqrt{(\sigma / \rho-1) g d^{3}}$ in which $q_{s}^{\prime}, q_{B}^{\prime}, q_{T}^{\prime}=$ the measured suspended, bed load and total sediment yield from the basin respectively in tons per $\mathrm{km}^{2}$ per storm, $\mathrm{t}_{\mathrm{R}}=$ equivalent rainfall duration time in minutes which would give the same amount of rainfall volume for $t_{R}$ as for the mean rainfall intensity and the actual rainfall duration and sand diameter $d$ is used interchangeably with the median sand diameter $\left(d \equiv d_{50}\right)$. The ratio of bed load to suspended load for this basin was about $7 \%$ for the 1986 storms. The observed critical rainfall intensity for no sediment discharge was $4 \sim 6 \mathrm{~mm} / \mathrm{hr}$ whereas by Eq. 4(b) it was found to be about $3 \mathrm{~mm} / \mathrm{hr}$.

\section{RESULTS AND DISCUSSION}

Results of sediment transport rates are shown in Fig. 4. Two parameters are further adopted:

Score $=1$ for $0.5 \leq \frac{\mathrm{q}_{\mathrm{B}^{*} \mathrm{i}}^{\prime}}{\mathrm{q}_{\mathrm{B}_{\mathrm{i}}}} \leq 2.0 ; \mathrm{R}=1-\sum_{\mathrm{i}=1}^{\mathrm{N}}\left(\mathrm{q}_{\mathrm{B}^{*_{\mathrm{i}}}}^{\prime}-\bar{q}_{B^{*}}\right)^{2} / \sum_{\mathrm{i}=1}^{\mathrm{N}}\left(\mathrm{q}_{\mathrm{B}^{*} \mathrm{i}}^{\prime}-\mathrm{q}_{\mathrm{B}^{*}}\right)^{2} ; \bar{q}_{B^{*}}=\frac{1}{\mathrm{~N}} \sum_{\mathrm{i}=1}^{\mathrm{N}} \mathrm{q}_{\mathrm{B}^{*} \mathrm{i}}$

in which $q_{B *_{i}}^{\prime}, q_{B *_{i}}=$ computed and measured sediment transport rates as either total or bed load for the $\mathrm{i}$-th storm respectively. The Score indicates nearness to actual measured value, $\mathrm{N}=$ number of storms and $\mathrm{R}$ indicates consistency among the different storms. The Score and $\mathrm{R}$ respectively for each model were as follows: $\operatorname{RBB}(6,0.366) ; \operatorname{FBB}(8,0.681)$; $\operatorname{RGB} 1(5,0.353)$; $\operatorname{RGB} 2(7.0 .672) ; \operatorname{FGB}(7,0.577)$; FWB1(4, 0.320); FWB2 $(5,0.488)$ and FWB3(7, 0.596) In Fig. 4(a) the one-term dimensional models are simple to calibrate but they have limited transferability to another basin or season beyond the water year of calibration. The dimensional models in Fig. 4(a) are not as flexible as that in Fig. 4(b). Model RGB2 was superior to FGB1. Further, model RGB2 and FGB performed almost equally. The white box models based on average bed shear stress (FWB1), based on bare area ratio (FWB2) and on pick-up rate of rainfall impact and flow (FWB3) are shown in Figs. 4(e), (f) and (g) respectively. Model FWB3 was better in comparison to the other two white-box models (FWB1 \& FWB2) in both accuracy and consistency. 

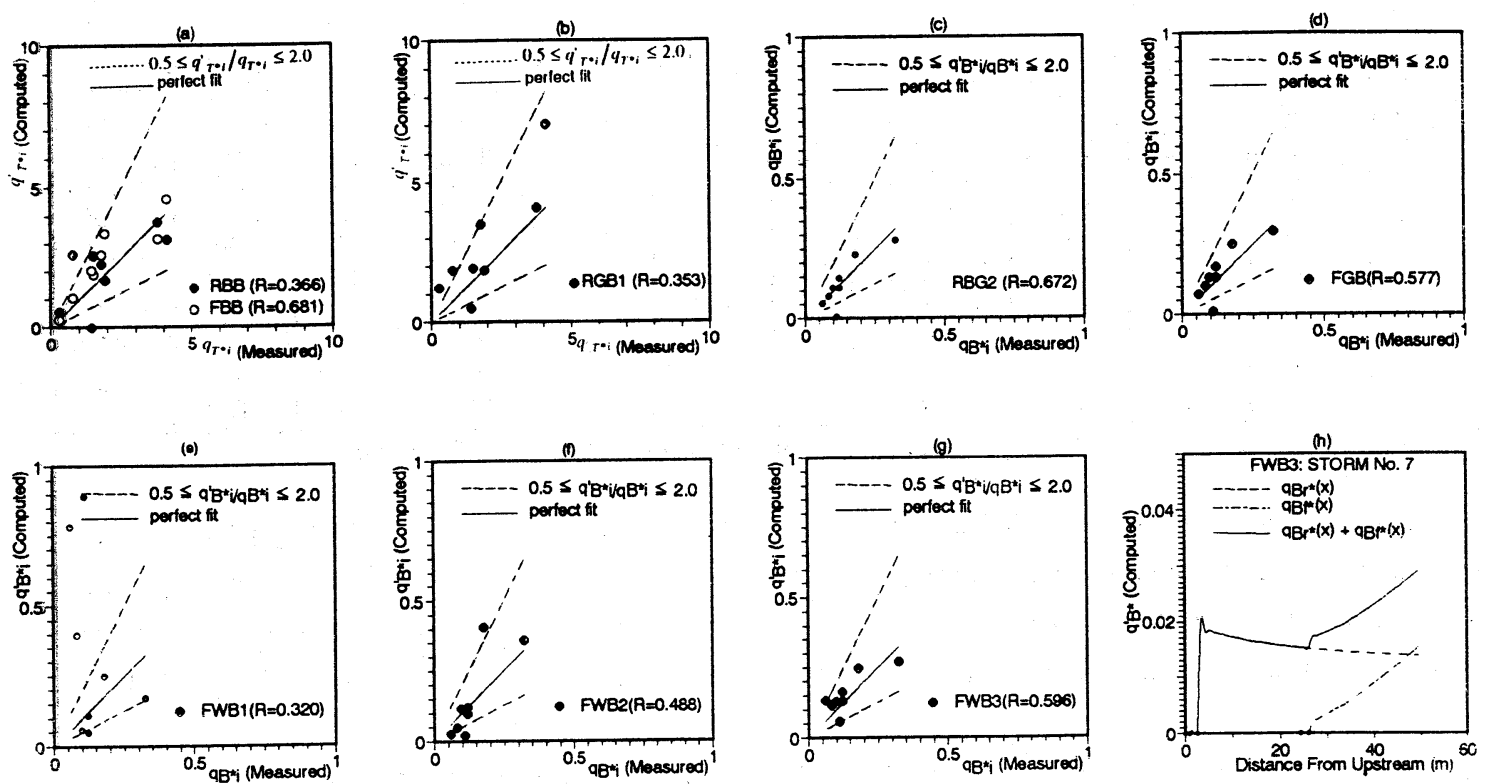

|Conversions: $q_{B^{*}} \equiv 0.08 q_{T^{*}} ; q_{s^{*}} \equiv 0.92 q_{T^{*}}$ |

(Note: Sediment transport rates reported as bed load except for models RBB, FBB \& RGB 1 where rates are reported as total load)

Fig. 4 Results of Model Computations for the Storms of 1986 in Katiorin Experimental Basin, Kenya

\section{CONCLUSIONS}

Various models for prediction of sediment yield and transport classified according to the consideration of physical factors are discussed. The performance of the models is evaluated by use of field data from the tropical ASAL of Eastern Africa. With correct calibration and determination of principal parameters such as length of slope, soil cover and elements in which morphological factors may be uniform, it is possible to select suitable models from these or others that may predict sediment transport rates fairly accurately. The results of this paper may contribute towards filling the gap of information in the area of sediment budget for tropical arid and semi-arid climates.

\section{REFERENCES}

(1). Ashida, K., T. Takahashi and H. Mizuyama(1978), " Study on Bed Load Equations for Mountain Streams", Jour. Japan Soc. Erosion Control Eng., 107, pp. 9-17 (in Japanese).

(2). Best A.C. (1950), "Emphirical Formulae for Terminal Velocity of Water Drops Falling Through the Atmosphere ", Quart. J. Metcr. Soc., 76, pp. 302-311.

(3). Bryan R.B., I.A. Campbell and R.A. Sutherland (1988), " Fluvial Geomorphic Processes in Semi-Arid Ephemeral Catchments in Kenya and Canada ", Cantena Supplement 13, pp. 13-35.

(4). Ellison, W.D. (1947), " Soil Erosion Studies. II. Soil Detachment Hazard by Raindrop Splash ", Agric. Engng., 28, pp. 197-201.

(5). Fukada M., T. Fujiwara and T. Kusaka(1992), " Measurements of Detached Soil Particles by Applying Positive Pressure Impulse Produced by the Impact of a Water Drop on the Surface of Water", Fundamental Studies on the Mechanism of Erosion (IV), Trans., JSIDRE, 159, pp. 37 - 43 (in Japanese).

(6). Komura S. (1976), " Hydraulics of Slope Erosion by Overland Flow ", Jour. of Hydraulic Div. ASCE, 102, No. HY 10, pp. $1573-1586$.

(7). Makhanu K.S. (1991), "The Effect of Storm Movement on the Time of Concentration", Proc. 13th WFEO Gen. Assembly \& Intl. Congress on Alleviation of Natural Disast., Arusha, Tanzania, pp. KSM1-12.

(8). Makhanu K.S., S. Murakami and H. Nakagawa (1995), " Computation of Sediment Yield From Rainfall Impact Energy ", Proc. JSCE, Paper No. II-248, pp. 496 - 497.

(9). Musgrave, G.W. (1935), " The Infiltration Capacity of Soils in Relation to the Control of Surface Runoff and Erosion ". Jour. Am. Soc. Agronomy, 27, pp. 336 - 45.

(10). Nakagawa H. and T. Tsujimoto (1980), " Sand Bed Instability due to Bed Load Motion ", Jour. Hydr. Div., ASCE, 106, No. HY12, pp. 2029 - 2051. 